\title{
THE GASTRIC VASA BREVIA
}

\author{
H. M. HELM \\ From the Anatomical Laboratory of the University of Wisconsin
}

THIRTY-SEVEN FIGURES,

The gastric vasa brevia are those branches of the splenic artery and veins and their terminal divisions which pass by way of the gastro-splenic omentum to the fundus of the stomach.

In this consideration of the gastric vasa brevia the aim has been: first, to determine the most usual arrangement of these vessels in the adult, as regards number, size, origin, and distribution; and, second, to ascertain the time and manner of their development in the embryo. Conclusions regarding the adult arrangement are based on a series of twenty-five drawings of the spleens and splenic vessels of as many dissecting-room subjects. The first eight drawings were made by Dr. Bunting, and it was at his suggestion that the study was carried farther.

Number. A glance at the outstretched arteries (figs. 1-25), shows that there were three in two cases, four in six, five in six, six in eight, and seven in three. Thus there are usually more than three and seldom as many as seven; the most usual number is six, but four and five are hardly less frequent. The average number in the series was a little over five.

Size. The vasa brevia are always small. They were measured in fifteen of the subjects examined and in no case were they more than $4 \mathrm{~mm}$. in diameter. Not infrequently they were mere threads, less than $0.5 \mathrm{~mm}$. in diameter; the most common size was about $2 \mathrm{~mm}$.

Origin. The splenic artery ordinarily divides into two main divisions, a superior for the supply of the upper half of the spleen, and an inferior for the supply of the lower half of the spleen, a part of the great omentum and a part of the greater curvature 

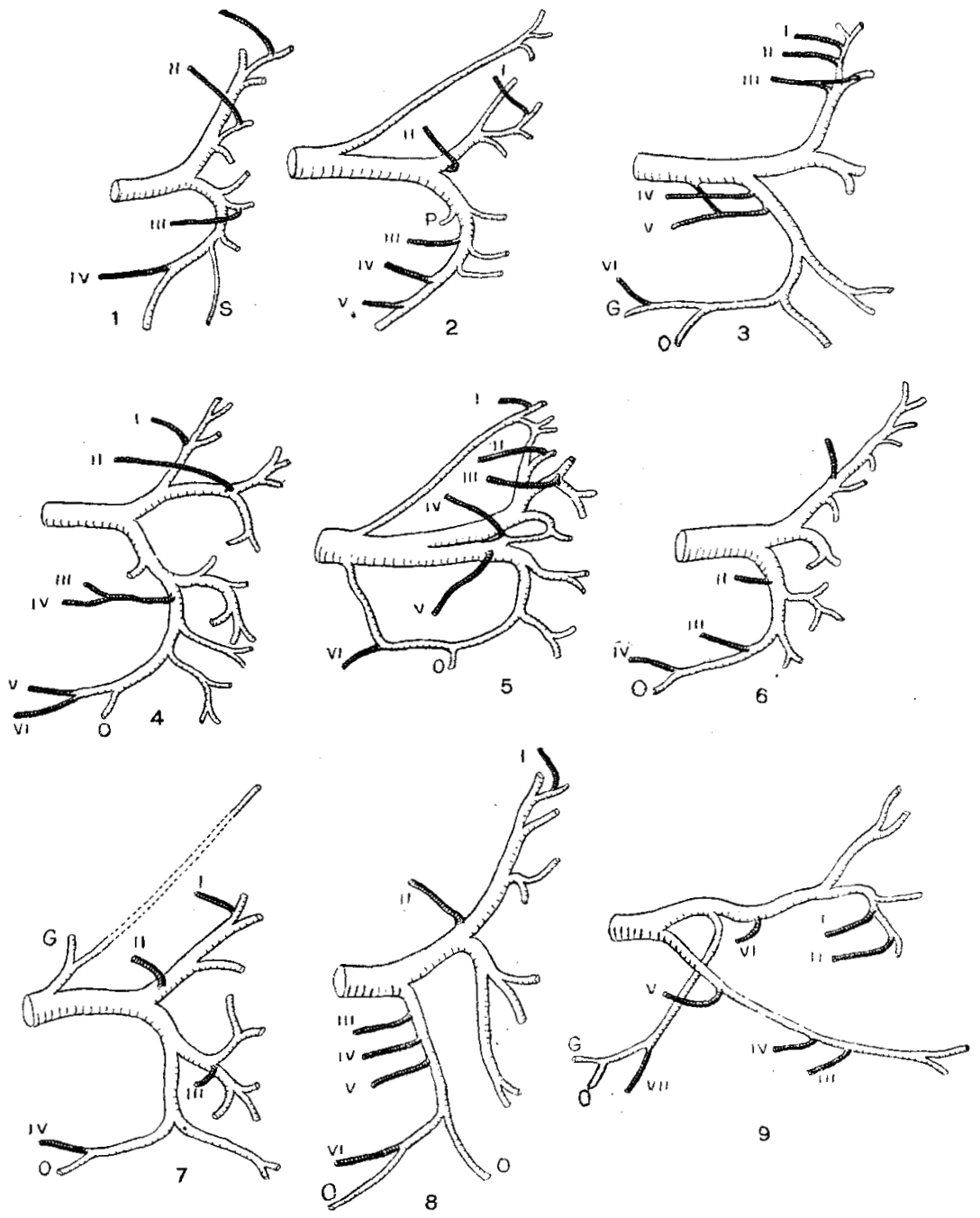

Figs. 1-25 Diagrammatic sketches of twenty-five specimens showing the origin of the vasa brevia arteries of the stomach from the splenic artery and its branches. The vasa brevia are shown dark. The lighter branches not otherwise labeled are splenic branches. $O$, gastro-epiploic; $P$, pancreatic branch $S$ (fig. 1), branch to accessory spleen. 

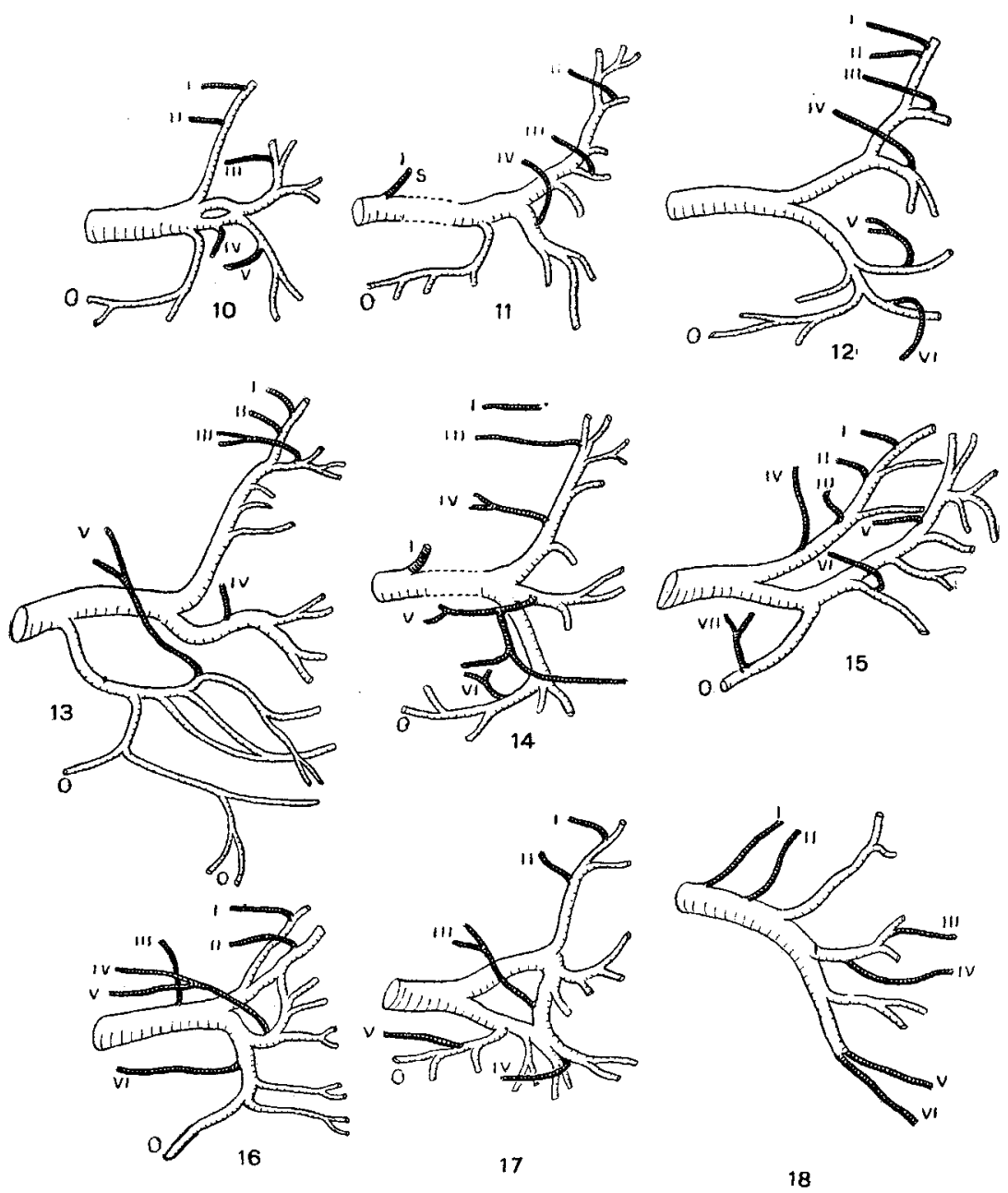

of the stomach. The left gastro-epiploic may be a branch of the inferior division, as was true in thirteen cases, or it may be a branch of the main splenic trunk, occurring before the division into superior and inferior divisions. In any case the gastroepiploic trunk usually gives off vasa brevia (e.g., this was true in thirteen of the seventeen gastro-epiploic vessels examined). It was true in every one of the eight instances in which the gastroepiploic arose from the splenic artery proper. 


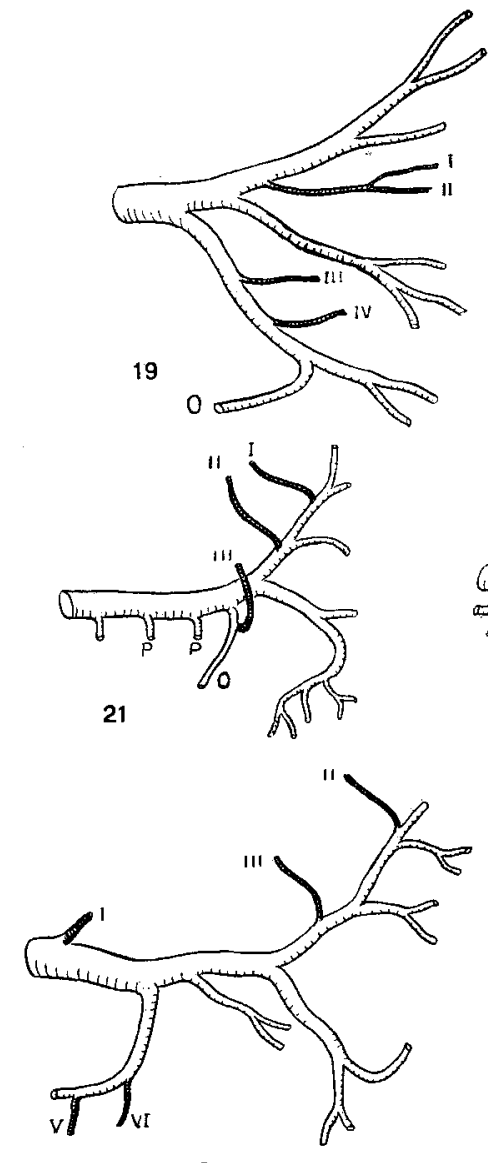

24

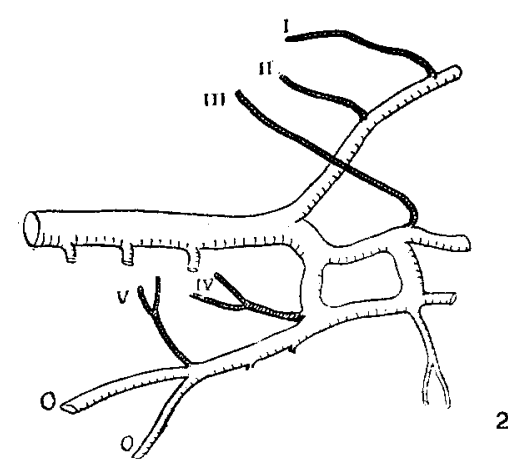

20
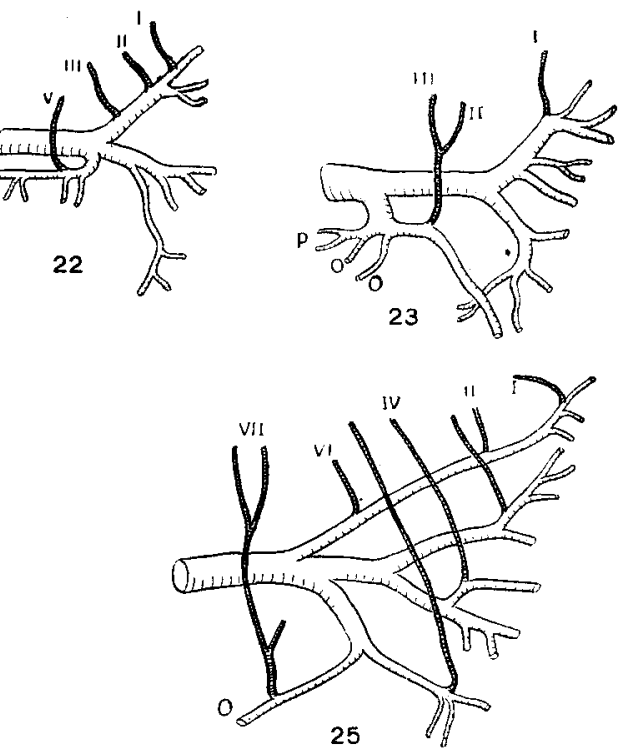

There may be anastomosis between the superior and inferior divisions, as in figures 16 and 17, and there may be accessory superior branches from the splenic trunk, as in figures 2 and 5 , or accessory inferior branches as in figure 9.

As we have seen, the vasa may arise from (1) the splenic artery itself; (2) the accessory splenic branches springing from the main splenic trunks midway between the coeliac axis and the spleen, and (3) the superior and inferior divisions (the latter including the gastro-epiploic) and their secondary branches. 
Vasa brevia arising from the splenic artery itself are the exception; figures 9 and 16 show them. That shown in figure 9 was about $1 \mathrm{~mm}$. in diameter and it passed to the dorsum of the stomach, low down on the fundus (VI, fig. 26). That shown in figure 16 was larger ( 3 or $4 \mathrm{~mm}$.) as were all the vasa brevia in this specimen. It passed to the dorsum of the stomach toward the cardiac orifice. Both these vessels arose close to the spleen. More frequently the splenic artery gives off a gastric branch near its origin. This branch may be a typical vas breve, but as often it is a coronary or accessory coronary branch destined for the supply of the lesser curvature. Such a branch was present in four of the twenty-five specimens, as shown in figures $11,14,18$ and 24 . In figure 11 the vessel was $1.5 \mathrm{~mm}$. in diameter and about $5 \mathrm{~cm}$. long. It arose $3 \mathrm{~cm}$. from the origin of the splenic artery and $9 \mathrm{~cm}$. from the hilus of the spleen, and passed to the dorsum of the fundus about $3.5 \mathrm{~cm}$. below and 2 $\mathrm{cm}$. to the left of the cardiac orifice. It did not anastomose with any other vessel; it was a true vas breve.

The vessel shown in figure 18 was similar in size, origin, and distribution; it was also a true vas breve. This specimen also showed a vas breve originating nearer to the spleen and similar to those described as occurring in figures 9 and 16 .

In case of those splenic arteries which give off accessory splenic branches before reaching the spleen, the accessory branches almost always give rise to vasa brevia. Such branches were present in five cases, and all but one (fig. 2) gave off vasa brevia. But since these branches occur in but twenty per cent of the cases, we come to the rather self-evident conclusion, that typically, the vasa brevia arise from the superior and inferior splenic divisions and their branches.

We have said the usual number of vasa brevia is five or six. Table 1 shows the number of branches arising from the superior and inferior divisions.

The vasa brevia arising from the superior division tend to be smaller than those arising from the inferior. This was true in ten of the fifteen cases in which comparative measurements were made. In another case the smallest vessel arose from the supe- 

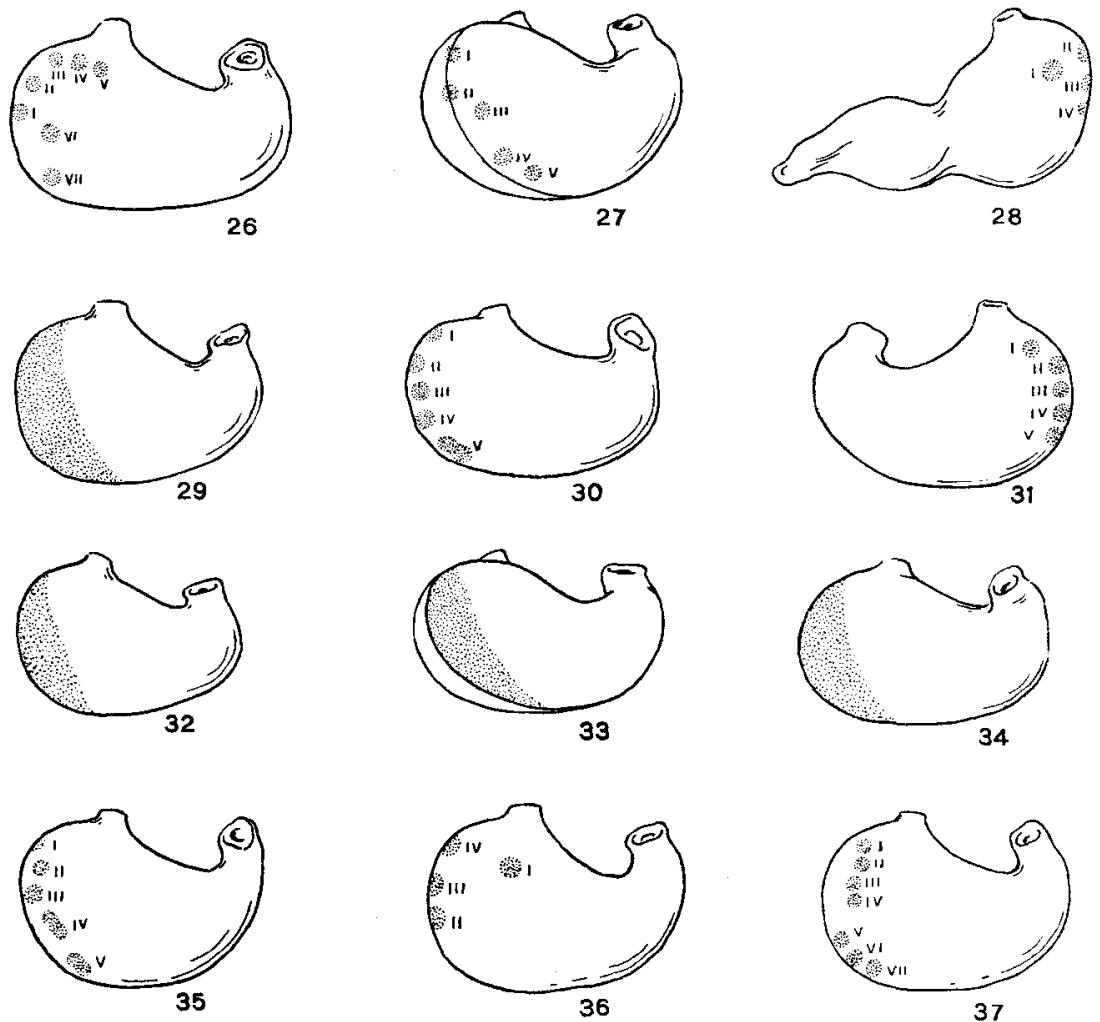

Figs. 26-37 Diagrammatic sketches of twelve stomachs, showing the distribution of the vasa brevia of twelve of the specimens illustrated in figures 9 to 25 . The distribution of the vasa brevia of the specimen shown in figure 9 is illustrated in figure 26; that of figure 10 in figure 27 ; figure 11 in figure 28; figure 12 , in figure 29 ; figure 13 , in figure 30 ; figure 14, in figure 31 ; figure 15, in figure 32 ; figure 17, in figure 33 ; figure 18 , in figure 34 ; figure 20 , in figure 35 ; figure 24 , in figure 36; figure 25 in figure 37 . In figure 36 the area of distribution of branch $\mathrm{V}$ was not determined accurately and is not shown. This is also true of branch VI in figure 31. In figures $29,32,33$ and 34 the general area of distribution is shown instead of the approximate area of each branch. In figures 27 and 33 the stomach is turned so as to show the line of omental attachment. Figures 28 and 31 show the ventral, the other figures the dorsal surface of the stomach. In figures 28 and 31 the area of distribution of branch $I$ is really on the dorsal surface so that the stomach is represented as transparent over this area. The other branches are distributed near the line of omental attachment. 
TABLE 1

\begin{tabular}{llllllllllllll}
\hline Figs. ....... & 1 & 2 & 3 & 4 & 5 & 6 & 7 & 8 & 9 & 10 & 11 & 12 & 13 \\
\hline Sup........ & 2 & 2 & 3 & 2 & 3 & 1 & 2 & 2 & 3 & 3 & 2 & 4 & 3 \\
Inf......... & 2 & 3 & 3 & 4 & 2 & 3 & 2 & 4 & 4 & 2 & 1 & 2 & 2 \\
\hline
\end{tabular}

\begin{tabular}{|c|c|c|c|c|c|c|c|c|c|c|c|c|}
\hline Figs............ & 14 & 15 & 16 & 17 & 18 & 19 & 20 & 21 & 22 & 23 & 24 & 25 \\
\hline $\operatorname{Sup} \ldots \ldots \ldots \ldots \ldots$ & 3 & 4 & 2 & 2 & 2 & 2 & 3 & 2 & 3 & 1 & 2 & \\
\hline Inf............ & 2 & 3 & 2 & 3 & 2 & 2 & 2 & 1 & 1 & 2 & 2 & 3 \\
\hline
\end{tabular}

rior division, but the other superior branches were as large as the inferior. In the other four instances all the vessels were of about the same size. In many cases the superior branches, notably the first two, are mere threads, less than $0.5 \mathrm{~mm}$. in diameter, whereas the inferior branches are apt to be 1.5 to $3 \mathrm{~mm}$. in diameter.

A glance at the sketches shows that the point of origin of most of the vasa brevia is very uncertain so soon as one attempts to localize it to a secondary branch of the superior or inferior division. This is because the secondary splenic branches themselves are so variable. However, the first vas breve is relatively constant. It is small, as we have said, and usually arises from the highest splenic branch of the superior divisionthe terminal branch, virtually - close to where it sinks into the spleen. This was the case in sixteen of the twenty-five spleens examined; in another it arose slightly lower, from the superior division itself; in another it arose from the second instead of the first splenic branch; and in two others it arose from a superior accessory splenic branch. Its distribution is likewise relatively constant. Typically, it passes to the highest point on the fundus. It is not always the highest branch, however; thus in figure 15, vessel IV had the highest position on the stomach.

The second vas breve usually arises from the superior division or from one of its uppermost branches close to the first, runs parallel with the first, and has the next lower position on the fundus; like the first it is usually small. The third also usually 
rises from the superior division in case there are five or six vessels in all. The fourth arises close to the bifurcation of the splenic artery, sometimes from one main division, sometimes from the other. The fifth and sixth arise from the inferior division, frequently from the gastro-epiploic trunk. The vessels tend to run parallel and to reach the stomach in the order of their origin.

Distribution. A consideration of the distribution of the vasa brevia gives a somewhat more satisfactory result. Since the vessels run in the gastro-splenic omentum, they reach the greater curvature of the stomach in the region of the fundus. Some small twigs may pass to the fundus just ventral to the line of omental attachment, but in every case virtually the whole area of vasa brevia supply was dorsal to the line of omental attachment: i.e., on the dorsal or original right side of the fundus. The uppermost vasa brevia tended to remain practically in the line of omental attachment; the lower branches, on the other hand, usually passed well onto the dorsum. In no case did a vessel pass much distance onto the ventral surface of the fundus.

In no case did a vas breve form anastomotic loops with other vessels. Thus they differ from all other gastric vessels, i.e., the coronary and gastro-epiploic branches; they are end arteries.

A glance at the sketches, figures 26 to 37 , will indicate the location and extent of the area of distribution of the vasa brevia. In figure 31 the vessels are confined to the region of omental attachment, as many twigs passing anteriorly as posteriorly. No anterior twigs pass far, however, while the first vessel is distinctly dorsal in position. In figures 27 and 28 , likewise, the vessels remain close to the line of omental attachment, though the tendency is toward dorsal distribution. In all other cases the area is distinctly dorsal to the line of attachment of the omentum. Furthermore, it is to the left of a line dropped from the esophagus to the greater curvature. That is to say, the vasa brevia are confined to the fundus. Figure 26 illustrates the fact previously mentioned that vessels arising from the inferior division do not necessarily take the lower positions on the stomach.

Development. The vasa brevia develop very early in the embryonic life as primary branches of the splenic artery. They 
later become tributary to the splenic arteries as these are differentiated and in adult life are always small. Their number and origin is variable, but their distribution is constant: they pass practically wholly to the dorsum of the fundus. They are end arteries and in no case anastomose with other vessels. In a pair of duplicate twin fetuses there were in one body five vessels, in the other six and the origins of the vessels differed in the two specimens.

To summarize: In the adult there are usually five or six vasa brevia, but there may be fewer or more. The vessels usually arise from the superior and inferior divisions of the splenic artery, but they may arise from the main trunk of the splenic artery or from accessory splenic branches; the branches of the superior division tend to be smaller, more numerous and to take a higher position on the fundus than the inferior branches, but the reverse may be true. The vasa brevia are never very large -at least under normal conditions; they are terminal or end arteries; they pass to the dorsum of the fundus of the stomach. 